\title{
Chronic Kidney Disease among Diabetes Patients in Ethiopia: A Systematic Review and Meta-Analysis
}

\author{
Wondimeneh Shibabaw Shiferaw (iD, ${ }^{1}$ Tadesse Yirga Akalu, ${ }^{2}$ and Yared Asmare Aynalem (iD \\ ${ }^{1}$ Department of Nursing, College of Health Science, Debre Berhan University, Debre Berhan, Ethiopia \\ ${ }^{2}$ Department of Nursing, College of Health Science, Debre Markos University, Debre Markos, Ethiopia \\ Correspondence should be addressed to Wondimeneh Shibabaw Shiferaw; wshibabaw21@gmail.com
}

Received 29 July 2020; Revised 23 September 2020; Accepted 26 September 2020; Published 10 October 2020

Academic Editor: Franca Anglani

Copyright (c) 2020 Wondimeneh Shibabaw Shiferaw et al. This is an open access article distributed under the Creative Commons Attribution License, which permits unrestricted use, distribution, and reproduction in any medium, provided the original work is properly cited.

\begin{abstract}
Background. Though different primary studies have reported the burden of chronic kidney disease among diabetes patients, their results have demonstrated substantial variation regarding its prevalence in Ethiopia. Therefore, this study aimed to estimate the pooled prevalence of chronic kidney disease and its associated factors among diabetes patients in Ethiopia. Method. PubMed, African Journals Online, Google Scholar, Scopus, and Wiley Online Library were searched to identify relevant studies. The $I^{2}$ statistic was used to check heterogeneity across the included studies. A random-effects model was applied to estimate the pooled effect size across studies. A funnel plot and Egger's regression test were used to determine the presence of publication bias. All statistical analyses were performed using STATA $^{\mathrm{TM}}$ version 14 software. Result. In this meta-analysis, a total of 12 studies with 4,075 study participants were included. The estimated prevalence of CKD among diabetes patients was found to be $35.52 \%$ (95\% CI: $25.9-45.45, I^{2}=96.3 \%$ ) for CKD stages 1 to 5 and $14.5 \%$ (95\% CI: $\left.10.5-18.49, I^{2}=91.1 \%\right)$ for CKD stages 3 to 5 . Age greater than 60 years (OR=2.99; $95 \%$ CI: 1.56-5.73), female sex $(\mathrm{OR}=1.68 ; 95 \% \mathrm{CI}: 1.04-2.69)$, duration of diabetes $>10$ years $(\mathrm{OR}=2.76 ; 95 \% \mathrm{CI}: 1.38-5.51)$, body mass index $>30 \mathrm{~kg} / \mathrm{m}^{2}(\mathrm{OR}=2.06$; 95\% CI: $1.41-3.00)$, type 2 diabetes ( $\mathrm{OR}=2.54$; 95\% CI: $1.73-3.73)$, poor glycemic control ( $\mathrm{OR}=2.01$; $95 \%$ CI: $1.34-3.02)$, fasting blood glucose $>150 \mathrm{mg} / \mathrm{dl}(\mathrm{OR}=2.58 ; 95 \% \mathrm{CI}: 1.79-3.72)$, high density lipoprotein $>40 \mathrm{mg} / \mathrm{dl}(\mathrm{OR}=0.48 ; 95 \%$ CI: 0.30-0.85-25), systolic blood pressure $>140 \mathrm{mmHg}(\mathrm{OR}=3.26$; $95 \% \mathrm{CI}$ : 2.24-4.74), and diabetic retinopathy $(\mathrm{OR}=4.54$; $\mathrm{CI}: 1.08-25)$ were significantly associated with CKD. Conclusion. This study revealed that the prevalence of chronic kidney disease remains high among diabetes patients in Ethiopia. This study found that a long duration of diabetes, age $>60$ years, diabetic retinopathy, female sex, family history of kidney disease, poor glycemic control, systolic blood pressure, overweight, and high level of high-density lipoprotein were associated with chronic kidney disease among diabetic patients. Therefore, situation-based interventions and context-specific preventive strategies should be developed to reduce the prevalence and risk factors of chronic kidney disease among diabetes patients.
\end{abstract}

\section{Background}

Chronic kidney disease (CKD) is defined as structural/ functional abnormalities of the kidney or decreased GFR $<60 \mathrm{ml} / \mathrm{min} / 1.73 \mathrm{~m}^{2}$ for 3 months [1]. It is an emerging global public health problem [2]. Globally, in 2017, there were 697.5 million cases of all-stage CKD, and 1.2 million people died each year due to high economic cost treatment [3]. In addition, it has been estimated that, by the year 2030, approximately 2.3-7.1 million adults have died prematurely from lack of access to renal replacement therapy [4]. The burden of CKD has been increasing, particularly in Oceania,
sub-Saharan Africa, and Latin America [3]. Hence, developing countries have insufficient resources to address the CKD epidemic and its serious long-term complications. It has a significant economic burden, with treatment costs far exceeding preventive costs. For instance, a study performed in London revealed that the total yearly cost for the treatment of CKD was $£ 1.44$ to $£ 1.45$ billion, and more than half spent on renal replacement therapy, which was provided for $2 \%$ of the CKD population [5].

Although there is still uncertainty about the root cause of $\mathrm{CKD}$, studies suggest that numerous risk factors are responsible for CKD, such as obesity [6-11], old age 
[7-9, 11-14], hypertension [3, 7, 9-13, 15-17], diabetes mellitus $[3,7,8,10-12,16,18]$, male gender $[12,17]$, hyperlipidemia [7], use of nephrotoxic medications [7], family history of kidney disease [9, 11, 13], smoking [19], heavy drinking [19], HIV infection [13], electrolyte and acid-base disturbances [13], low-income occupation, use of traditional medication, and low hemoglobin [11]. Early detection and treatment of possible risk factors are readily available and often inexpensive. Patients with CKD often suffer from an increased risk of cardiovascular mortality [20], ischemic heart disease [21], stroke [22], peripheral vascular disease [23], gout [24], depression and anxiety [25, 26], and reductions in patients' quality of life and markedly increases health care costs [27]. Patients with CKD may eventually progress to end-stage kidney disease (ESKD), which is associated with a high burden of disease and significant costs of treatment [28].

Large differences have been reported in terms of the prevalence of CKD based on available studies. For instance, the prevalence of CKD among diabetes patients is $38.5 \%$ in Palestine [29], 34.7\% in Morocco [30], 18.2\% in Ethiopia [31], and 24.6\% in South Africa [32]. Evidence suggests that early detection and treatment of diabetes, hypertension, and other chronic diseases can improve renal outcomes and slow or prevent the progression of CKD [33]. Despite the availability of such interventions, the burden of CKD and its related risk factors remain understudied in developing countries. This would be due to low awareness among the public, health care workers, and government and other funders and may lead to the false perception that CKD is not an important problem in sub-Saharan Africa [34].

Although different primary studies have shown that the burden of CKD among diabetes patients is high and treatment options are expensive, their results have demonstrated substantial variation regarding its prevalence in Ethiopia. Given this, there is a strong imperative to fully understand the burden of CKD in the region. Therefore, this study aimed to estimate the pooled prevalence of CKD and its associated factors among diabetes patients in Ethiopia. This finding provides a scientific basis for a better understanding of the burden of CKD among diabetes mellitus patients and helps to design appropriate preventive strategies.

\section{Methods}

2.1. Data Source and Search Strategy. We conducted this systematic review and meta-analysis according to the protocol registered in PROSPERO (CRD42020204239), available at: https://www.crd.york.ac.uk/prospero/ display_record.php? $\mathrm{ID}=\mathrm{CRD} 42020204239$. The Preferred Reporting Items for Systematic Review and MetaAnalysis statement (PRISMA) guideline was used to report the pooled prevalence of CKD in patients with DM [35]. The literature was searched using PubMed, Scopus, Google Scholar, African Journals Online, and Wiley Online Library to identify published reports of kidney disease among diabetes patients in Ethiopia up to May 18, 2020. A manual search was performed for grey literature available on local university shelves and institutional repositories. Moreover, the reference lists of all retrieved articles were conducted to identify additional relevant research to minimize publication bias to possible levels. The search was restricted to full texts, free articles, human studies, and English language publications. Endnote X 8.1 reference manager software was used to search, collect, organize search outcomes, and remove duplicate articles. During the search, medical subheading $(\mathrm{MeSH})$ as well as plain text was used for the following keywords: "chronic kidney disease," "diabetic nephropathy," "chronic renal failure," "renal impairment," "proteinuria," "end-stage kidney/renal disease," "renal insufficiency," "diabetes mellitus," "type 2 diabetes mellitus," "type 1 diabetes mellitus," "insulin dependent diabetes," "non-insulin dependent diabetes", and "Ethiopia". We have followed the search protocol described in the previous publication [36], and we also used Boolean operators such as "AND" and "OR" which were used to combine search terms (Table 1).

2.2. Eligibility Criteria. Inclusion criteria for this study were as follows: (1) observational studies including cross-sectional studies, cohort studies (retrospective and prospective), and case-control studies that report a prevalence of CKD among diabetes patients in adults from Ethiopian were eligible for inclusion; (2) articles published in peer-reviewed journals or grey literature; and (3) articles published in English from inception to May 18, 2020. Furthermore, if different diagnostic criteria of CKD were found in a single study, our first choice was the Chronic Kidney Disease Epidemiology Collaboration (CKD-EPI), our second choice considered the Modification of Diet in Renal Disease (MDRD) study equation, and lastly, the Cockcroft-Gault formula in the main analyses. We excluded studies if (1) they were not fully accessible; (2) they possessed a poor quality score as per the stated criteria; (3) case series, letters, comments, and editorials; and/or (4) failed to measure the desired outcome (i.e., chronic kidney disease).

2.3. Outcome of Interest. The main outcome of interest was the prevalence of chronic kidney disease reported in the original paper both as a percentage and as the number of CKD cases $(n) /$ total number of participants $(N)$. CKD is defined as proteinuria, a creatinine clearance of less than $60 \mathrm{~mL}$ per min by the Cockcroft-Gault formula [37], or an estimated glomerular filtration rate (GFR) of less than $60 \mathrm{~mL}$ per min per $1.73 \mathrm{~m}^{2}$ by the Modification of Diet in Renal Disease (MDRD) equation [38] and Chronic Kidney Disease Epidemiology Collaboration (CKD-EPI) prediction equation [39].

2.4. Study Selection. Following the search, all identified citations were uploaded into EndNote version 8.1, and duplicates were removed. Titles and abstracts were then screened by two reviewers (WSS and YAA) for assessment against the inclusion criteria for the review. The full text of 
TABle 1: PubMed search history.

\begin{tabular}{|c|c|c|}
\hline Search & Search terms & Hits \\
\hline 1 & $\begin{array}{c}\text { Diabetes[tw] OR diabetes mellitus[tw] OR type } 1 \text { diabetes[tw] OR type } 1 \text { diabetes mellitus[tw] OR T1DM[tw] OR type } 2 \\
\text { diabetes[tw] OR type } 2 \text { diabetes mellitus[tw] OR T2DM[tw] }\end{array}$ & 623,574 \\
\hline 2 & $\begin{array}{c}\text { Chronic kidney disease }[\mathrm{tw}] \text { OR diabetic nephropathy[tw] OR chronic renal failure }[\mathrm{tw}] \text { OR renal impairment }[\mathrm{tw}] \text { OR } \\
\text { proteinuria }[\mathrm{tw}] \text { OR end-stage kidney/renal disease }[\mathrm{tw}] \text { OR renal insufficiency }[\mathrm{tw}]\end{array}$ & 191,757 \\
\hline 3 & $\# 1$ and \#2 & 168,020 \\
\hline 4 & Ethiopia[tw] OR ethio[tw] & 18,268 \\
\hline 5 & $\# 3$ and \#4 & 127 \\
\hline 6 & Limits: studies done in humans, English language, and full text & 48 \\
\hline
\end{tabular}

selected citations was assessed in detail against the inclusion criteria by two reviewers (TYA and YAA). Reasons for exclusion of full-text studies that did not meet the inclusion criteria were recorded and reported in the systematic review. Any disagreements that arose between the reviewers at each stage of the study selection process were resolved through discussion.

2.5. Data Extraction and Quality Assessment. After identifying articles for inclusion, two authors (WSS and TYA) performed data extraction. The Joanna Briggs Institute (JBI) tool was used for the data extraction [40]. For each included study, the following data were extracted: first/corresponding author, publication year, region, study design, sample size, data collection period, sampling technique, definition of kidney disease (microalbuminuria, albuminuria, macroalbuminuria, and estimated GFR (eGFR) decline), GFR equation/formula used, prevalence of CKD with its $95 \%$ confidence interval (CI), and associated factors. After data extraction, the third author (YAA) crosschecked both of the tables to ensure consistency. Any dispute that arose during data extraction was resolved by group consensus. The methodological quality of each included study was assessed using the Newcastle-Ottawa scale (NOS) [41]. This tool includes items that assess representativeness, response rate, the method of assessing outcomes, comparability of the subject, and the appropriateness of the statistical test used to analyze the data. Studies were included in the analysis if they scored $\geq 5$ out of 10 points in three domains of ten modified NOS components for observational studies [42]. Furthermore, quality assurance checks were performed by two authors (YAA and WSS). Any controversy related to each article was collectively resolved by all authors, giving their opinion and the final decision made by consensus (supplementary file 1).

2.6. Assessment of Risk of Bias in Included Studies. An assessment of the risk of bias was conducted on all included studies developed by Hoy et al. [43] to assess the external and internal validity of nonrandomized studies in meta-analyses. The Hoy score is marked out of ten, and studies were classified as "high risk of bias" (total score $\leq 4$ ), "moderate risk of bias" (total score between 5 and 7), or "low risk of bias" (total score between 8 and 10) (supplementary file 2). Two authors carried out the risk of bias assessment of the included studies.
2.7. Heterogeneity and Publication Bias. Cochran's $Q$ and the $I^{2}$ statistics were employed to investigate heterogeneity between studies [44], which estimates the percentage of total variation across studies due to true between-study differences rather than chance, with $I^{2}$ values of 25,50 , and $75 \%$ representing low, medium, and high heterogeneity, respectively. We explored sources of heterogeneity through subgroup analysis and metaregression analysis. Sensitivity analysis was also performed for the effect of each study on the overall prevalence. Publication bias was assessed by visually inspecting funnel plots and objectively using Egger's test [45].

2.8. Statistical Analysis. We used the DerSimonian-Laird random-effects models to generate the pooled prevalence of CKD due to the anticipation of substantial variations in CKD prevalence estimates across the included studies [46]. The pooled effect size (i.e., prevalence) with a 95\% confidence interval (CI) was generated and presented using a forest plot. All statistical analyses were performed using STATA $^{\mathrm{TM}}$ version 14 software [47]. All the results are reported using PRISMA checklist (supplementary file 3).

\section{Result}

3.1. Selection of the Studies. The initial search identified 490 articles, which were catalogued in citation management software (EndNote X 8.1). Of these, 455 studies were retrieved from PubMed (48), Scopus (20), Google Scholar (340), Wiley Online Library (19), and African Journals Online (59). On the other hand, the remaining 4 articles were found through manual search. Of them, 298 duplicate records were identified and removed. Following removal of duplicate studies, the titles and abstracts were evaluated, and 148 studies were excluded based on the prespecified inclusion criteria. Then, 44 studies were included for further assessment. After reviewing the full text, based on the predefined criteria and quality assessment, 12 articles were included for the final analysis (Figure 1).

3.2. Baseline Characteristics of the Study Participants. A total of 12 studies with 4,075 study participants were included in the review. Of these, 11 studies were used to estimate the pooled prevalence of $\mathrm{CKD}$ among diabetic patients. To estimate the pooled prevalence of CKD stages 1 to 5 among diabetes patients, seven studies [31, 48-53] were included. On the other hand, to estimate the pooled prevalence of CKD stages 3 to 5 , ten studies [31, 48, 50-57] were included. Regarding the study design, the majority (75\%) of the studies 


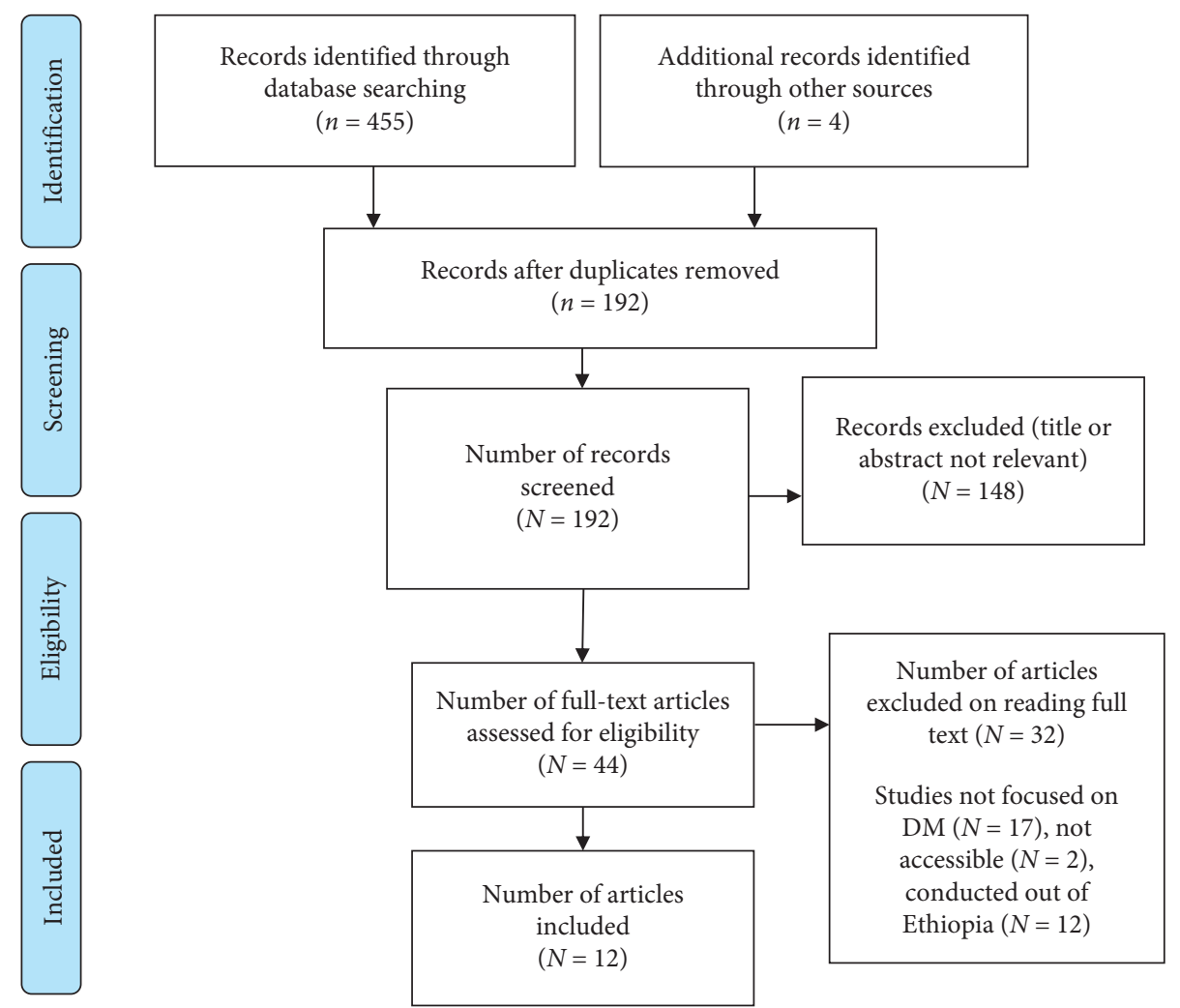

FIgURE 1: PRISMA flow diagram for selection of the included studies.

was cross-sectional. The subjects who participated in the studies were males and females aged $\geq 18$ years. The number of study participants per study ranged from 189 to 700 . The included studies applied various estimators of GFR; four of the studies [48, 55-57] used the CG formula in estimating GFR, four studies $[31,50,51,53]$ used the MDRD, and two studies $[52,54]$ used the CKD-EPI creatinine equation. The prevalence of CKD in patients with DM was obtained from various regions in Ethiopia; four studies were from Amhara $[50,51,53]$, three from Addis Ababa [55-57], three from Oromia [48, 49, 52], one each from Tigray [58] and SNNPR [31]. With regard to the sampling technique, four studies $[50,51,53,56]$ used systematic random sampling, three studies [31, 57, 58] used simple random sampling, two studies $[52,54]$ used convenience sampling, and three studies $[48,49,55]$ used the census sampling method. The quality score of the included studies was assessed based on the Newcastle-Ottawa quality score (Table 2).

3.3. Chronic Kidney Disease. The current meta-analysis showed that the overall prevalence of CKD among diabetes patients was $35.52 \%$ (95\% CI: $25.9-45.45, I^{2}=96.3 \%$ ) for CKD stages 1 to 5 and $14.5 \%$ (95\% CI: $\left.10.5-18.49, I^{2}=91.1 \%\right)$ for CKD stages 3 to 5 (Figure 2).

3.4. Subgroup Analysis. To identify the source of heterogeneity across the included studies, subgroup analysis was deployed using regions, type of DM, study design, GFR equation/formula, and sampling technique. Based on the subgroup analysis results, the pooled prevalence of CKD stages 3 to 5 was $17.47 \%$ in studies conducted in Addis Ababa, $16.79 \%$ in patients with T2DM, $16.79 \%$ in studies conducted using cohort study design, $18.96 \%$ among studies using CG as GFR equation/formula, and $19.22 \%$ in studies with census sampling technique (Table 3 ).

3.5. Metaregression Analysis. To identify the source(s) of heterogeneity for CKD stages 1 to 5 , metaregression analysis was undertaken by considering the year of publication, sample size, region, eGFR equation/formula, type of diabetes, study design, and sampling technique. However, our results showed that all covariates were not statistically significant for the presence of heterogeneity (Table 4 ).

3.6. Sensitivity. In sensitivity analyses using the leave-oneout approach, excluding none of the studies had a significant effect on the pooled burden estimates and measures of heterogeneity within primary studies. Therefore, sensitivity analyses using the random-effects model revealed that no single study influenced the overall prevalence of CKD stages 3 to 5 among diabetic patients (Figure 3).

3.7. Publication Bias. As shown in Figure 4, the visual inspection of the funnel plot showed that there was no publication bias among the included studies, as illustrated by the symmetrical distribution of the funnel plot, when CKD stages 3 to 5 was evaluated. Likewise, the result of Egger's test was not 
TABLE 2: Baseline characteristics of the included studies.

\begin{tabular}{|c|c|c|c|c|c|c|c|c|c|c|c|}
\hline $\begin{array}{l}\text { Author } \\
\text { publication }\end{array}$ & $\begin{array}{l}\text { Pub } \\
\text { year }\end{array}$ & Region & $\begin{array}{l}\text { Health } \\
\text { facility }\end{array}$ & $\begin{array}{l}\text { Study } \\
\text { design }\end{array}$ & $\begin{array}{l}\text { Type } \\
\text { of } \\
\text { DM }\end{array}$ & $\begin{array}{l}\text { Sample } \\
\text { size }\end{array}$ & $\begin{array}{c}\text { Prevalence } \\
\text { (\%) }\end{array}$ & $\begin{array}{l}\text { Diagnostic } \\
\text { criteria }\end{array}$ & $\begin{array}{l}\text { Sampling } \\
\text { technique }\end{array}$ & $\begin{array}{l}\text { Study } \\
\text { period }\end{array}$ & $\begin{array}{l}\text { Quality } \\
\text { score }\end{array}$ \\
\hline $\begin{array}{l}\text { Ayalneh } \\
\text { et al. [48] }\end{array}$ & 2019 & Oromia & $\begin{array}{c}\text { Asella } \\
\text { Referral } \\
\text { and } \\
\text { Teaching } \\
\text { Hospital }\end{array}$ & $\begin{array}{c}\text { Cross- } \\
\text { sectional }\end{array}$ & $\begin{array}{l}\text { Type } \\
1 \& 2\end{array}$ & 189 & 24.86 & Cockroft-gault & Census & $\begin{array}{c}\text { September } \\
2016 \text { to } \\
\text { December } \\
2018\end{array}$ & 6 \\
\hline $\begin{array}{l}\text { Fiseha } \\
\text { et al. [31] }\end{array}$ & 2014 & SNNPR & $\begin{array}{l}\text { Butajira } \\
\text { Hospital }\end{array}$ & $\begin{array}{c}\text { Cross- } \\
\text { sectional }\end{array}$ & $\begin{array}{l}\text { Type } \\
1 \& 2\end{array}$ & 214 & 18.2 & MDRD & $\begin{array}{l}\text { Simple } \\
\text { random }\end{array}$ & $\begin{array}{c}\text { September } \\
1 \text { to } \\
\text { October 31, } \\
2013\end{array}$ & 7 \\
\hline $\begin{array}{l}\text { Alemu } \\
\text { et al. [54] }\end{array}$ & 2020 & Amhara & $\begin{array}{c}\text { University } \\
\text { of Gondar } \\
\text { Hospital }\end{array}$ & $\begin{array}{c}\text { Cross- } \\
\text { sectional }\end{array}$ & $\begin{array}{l}\text { Type } \\
1 \& 2\end{array}$ & 272 & 14.3 & CKD-EPI & Convenience & $\begin{array}{c}\text { April } 2 \text { to } \\
\text { July } 31 \\
2018\end{array}$ & 6 \\
\hline Tefera [49] & 2014 & Oromia & $\begin{array}{l}\text { Shakiso } \\
\text { Health } \\
\text { Center }\end{array}$ & $\begin{array}{c}\text { Cross- } \\
\text { sectional }\end{array}$ & $\begin{array}{c}\text { Type } \\
2\end{array}$ & 700 & 30.8 & proteinuria & Census & $\begin{array}{c}\text { July } 2013 \text { to } \\
2014\end{array}$ & 7 \\
\hline $\begin{array}{l}\text { Abate et al. } \\
\text { [50] }\end{array}$ & 2013 & Amhara & $\begin{array}{l}\text { Fenote } \\
\text { Selam } \\
\text { Hospital }\end{array}$ & $\begin{array}{c}\text { Cross- } \\
\text { sectional }\end{array}$ & $\begin{array}{l}\text { Type } \\
1 \& 2\end{array}$ & 384 & 13.8 & MDRD & $\begin{array}{l}\text { Systematic } \\
\text { random }\end{array}$ & $\begin{array}{c}\text { February to } \\
\text { April } 2012\end{array}$ & 8 \\
\hline $\begin{array}{l}\text { Damtie } \\
\text { et al. [51] }\end{array}$ & 2018 & Amhara & $\begin{array}{l}\text { University } \\
\text { of Gonder } \\
\text { hospital }\end{array}$ & $\begin{array}{l}\text { Cross- } \\
\text { sectional }\end{array}$ & $\begin{array}{l}\text { Type } \\
1 \& 2\end{array}$ & 229 & 21.8 & MDRD & $\begin{array}{l}\text { Systematic } \\
\text { random }\end{array}$ & $\begin{array}{c}\text { February to } \\
\text { April } 2016\end{array}$ & 8 \\
\hline $\begin{array}{l}\text { Kumela } \\
\text { Goro et al. } \\
{[52]}\end{array}$ & 2019 & Oromia & $\begin{array}{l}\text { Jimma } \\
\text { University } \\
\text { Medical }\end{array}$ & $\begin{array}{c}\text { Cross- } \\
\text { sectional }\end{array}$ & $\begin{array}{l}\text { Type } \\
1 \& 2\end{array}$ & 208 & 26 & CKD-EPI & Convenience & Unspecified & 6 \\
\hline Moges [56] & 2016 & $\begin{array}{l}\text { Addis } \\
\text { Ababa }\end{array}$ & $\begin{array}{c}\text { Public } \\
\text { hospitals of } \\
\text { Addis } \\
\text { Ababa }\end{array}$ & $\begin{array}{c}\text { Cross- } \\
\text { sectional }\end{array}$ & $\begin{array}{l}\text { Type } \\
1 \& 2\end{array}$ & 355 & 19.1 & Cockcroft-Gault & $\begin{array}{l}\text { Systematic } \\
\text { random }\end{array}$ & $\begin{array}{c}\text { April } 20 \text { to } \\
\text { May } 12 \\
2016\end{array}$ & 7 \\
\hline $\begin{array}{l}\text { Fiseha and } \\
\text { Tamir [53] }\end{array}$ & 2020 & Amhara & $\begin{array}{c}\text { Dessie } \\
\text { Referral } \\
\text { Hospital }\end{array}$ & $\begin{array}{c}\text { Cross- } \\
\text { sectional }\end{array}$ & $\begin{array}{l}\text { Type } \\
1 \& 2\end{array}$ & 323 & 26.3 & MDRD & $\begin{array}{l}\text { Systematic } \\
\text { random }\end{array}$ & $\begin{array}{c}\text { February } 1 \\
\text { to July } 30 \\
2016\end{array}$ & 7 \\
\hline $\begin{array}{l}\text { Geletu } \\
\text { et al. [55] }\end{array}$ & 2018 & $\begin{array}{l}\text { Addis } \\
\text { Ababa }\end{array}$ & $\begin{array}{l}\text { St. Paul's } \\
\text { Hospital }\end{array}$ & $\begin{array}{l}\text { Cohort } \\
\text { study }\end{array}$ & $\begin{array}{c}\text { Type } \\
2\end{array}$ & 435 & 14.25 & Cockcroft-Gault & Census & Unspecified & 6 \\
\hline $\begin{array}{l}\text { Tamiru } \\
\text { et al. [57] }\end{array}$ & 2019 & $\begin{array}{l}\text { Addis } \\
\text { Ababa }\end{array}$ & $\begin{array}{c}\text { Black Lion } \\
\text { Specialized } \\
\text { Hospital }\end{array}$ & $\begin{array}{l}\text { Cohort } \\
\text { study }\end{array}$ & $\begin{array}{c}\text { Type } \\
2\end{array}$ & 346 & 19.65 & Cockcroft-Gault & $\begin{array}{l}\text { Simple } \\
\text { random }\end{array}$ & $\begin{array}{c}\text { March } 1 \text { to } \\
\text { April } 28 \\
2019\end{array}$ & 8 \\
\hline $\begin{array}{l}\text { Hintsa } \\
\text { et al. [58] }\end{array}$ & 2017 & Tigray & $\begin{array}{l}\text { Ayder } \\
\text { Referral } \\
\text { Hospital }\end{array}$ & $\begin{array}{c}\text { Case } \\
\text { control }\end{array}$ & $\begin{array}{l}\text { Type } \\
1 \& 2\end{array}$ & 420 & - & Not specified & $\begin{array}{l}\text { Simple } \\
\text { random }\end{array}$ & $\begin{array}{c}\text { February } 14 \\
\text { to May } 8 \\
2016\end{array}$ & 7 \\
\hline
\end{tabular}

MDRD: Modification of Diet in Renal Disease equation; CKD-EPI: Chronic Kidney Disease Epidemiology Collaboration prediction equation.

statistically significant for the presence of publication bias $(P=0.806)$. On the other hand, when CKD stages 1 to 5 were analyzed, only 7 studies were included. Therefore, we did not display the funnel plot in this part, as the analyses are likely underpowered.

3.8. Factors Associated with Chronic Kidney Disease. Based on this meta-analysis, chronic kidney disease among diabetes patients in the Ethiopian context was associated with the duration of DM, female sex, age $>60$ years, family history of $\mathrm{CKD}, \mathrm{BMI} \geq 30 \mathrm{~kg} / \mathrm{m}^{2}$, type 2 diabetes, FBG $>150 \mathrm{mg} / \mathrm{dl}, \mathrm{HbAlc}>7 \%$, HDL $\geq 40 \mathrm{mg} / \mathrm{dl}$, triglyceride $>150 \mathrm{mg} / \mathrm{dl}$, and systolic blood pressure $>140 \mathrm{mmHg}$ [31, 48, 51, 52, 54, 55, 57].
3.8.1. Sociodemographic Factors. The majority of the reports described the effects of age, sex, family history of CKD, and residence on $\mathrm{CKD}$ in patients with DM. Of these reports, only those that described the data in terms of the odds ratio, relative risk, and categorical variables were included. In the present analysis, the pooled effect of four studies $[31,51,53,54]$ showed that age greater than 60 years was statistically associated with CKD in patients with DM $(\mathrm{OR}=2.99 ; 95 \% \mathrm{CI}: 1.56,5.73)$. The heterogeneity test $\left(I^{2}=53.4 \%\right)$ showed no significant evidence of variation across studies. Additionally, the pooled effect of eight studies $[31,48,49,51-53,55,56]$ showed that female sex had higher odds of CKD in patients with DM (OR $=1.68$; 95\% CI; 1.04 , 2.69) than male sex. The heterogeneity test $\left(I^{2}=82.9 \%\right)$ showed significant evidence of variation across studies. 


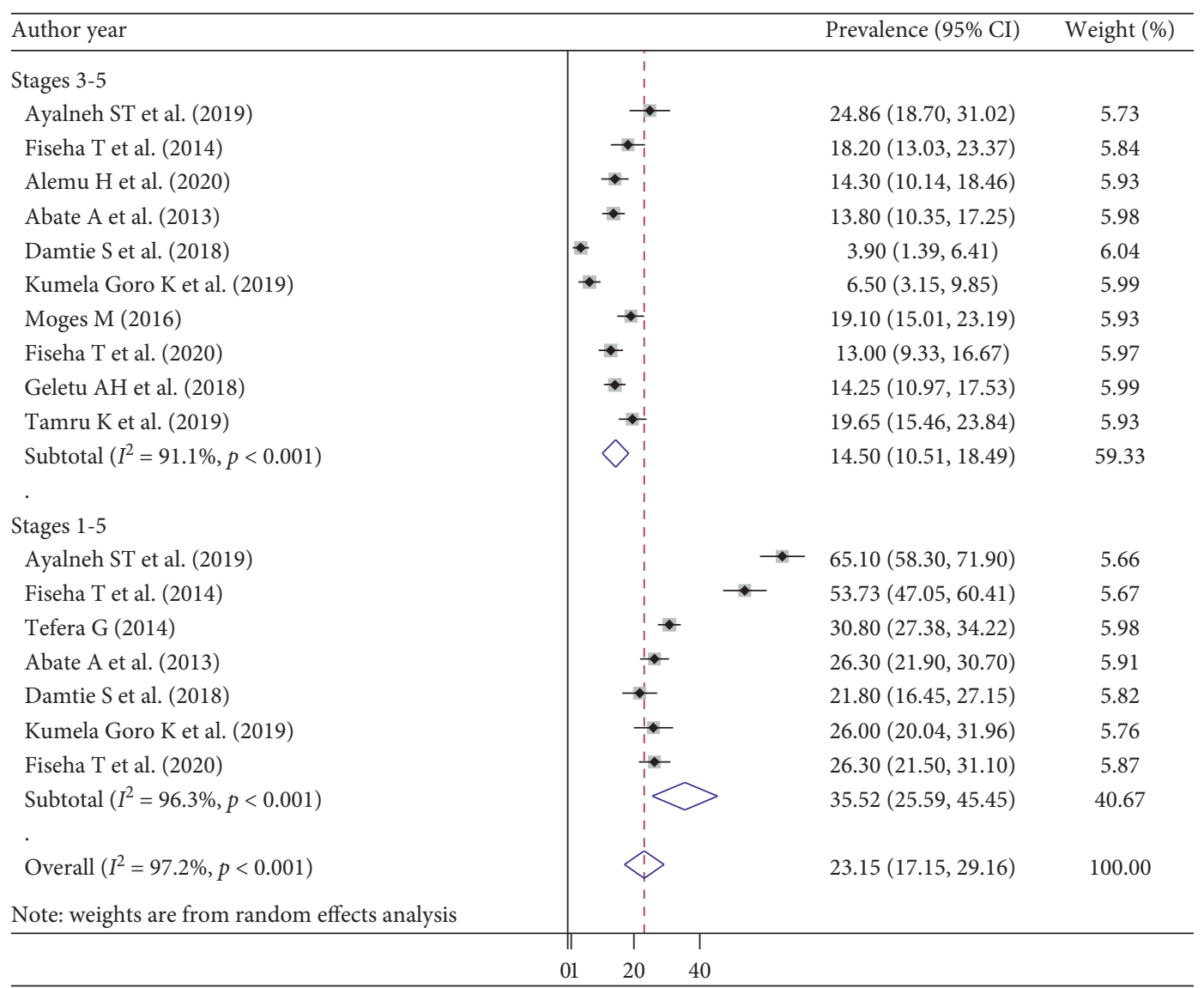

FIgUre 2: Pooled prevalence of chronic kidney disease (stages 1 to 5 and stages 3 to 5) among diabetes patients.

TABLE 3: The results of subgroup analysis by different categories of the studies.

\begin{tabular}{|c|c|c|c|c|c|c|}
\hline Subgroup & Category & No. of studies & Sample size & $\begin{array}{c}\text { Stages } 3-5 \\
\text { Prevalence }(95 \% \mathrm{CI})\end{array}$ & $P$ value & $I^{2}(\%)$ \\
\hline \multirow{3}{*}{ Region } & Amhara & 4 & 1,208 & $11.13(5.47,16.79)$ & $<0.001$ & 91.1 \\
\hline & Addis ababa & 3 & 1,136 & $17.47(13.88,21.05)$ & 0.073 & 61.8 \\
\hline & Others & 3 & 611 & $16.3(5.13,27.46)$ & $<0.001$ & 93.8 \\
\hline \multirow{2}{*}{ Study design } & Cohort & 2 & 781 & $16.79(11.51,22.07)$ & 0.047 & 74.7 \\
\hline & Cross-sectional & 9 & 2,874 & $13.92(9.23,18.16)$ & $<0.001$ & 91.8 \\
\hline \multirow{3}{*}{ Type of DM } & Type 2 & 2 & 781 & $16.79(11.51,22.07)$ & 0.047 & 74.7 \\
\hline & Type $1 \& 2$ & 8 & 2,174 & $13.92(9.23,18.61)$ & $<0.001$ & 91.8 \\
\hline & MDRD & 4 & 1,150 & $12.02(5.62,18.42)$ & $<0.001$ & 92.4 \\
\hline \multirow[t]{2}{*}{ GFR equation/formula } & CKD-EPI & 2 & 480 & $10.3(2.66,17.94)$ & 0.004 & 87.8 \\
\hline & CG & 4 & 1,325 & $18.96(14.93,22.99)$ & 0.014 & 71.8 \\
\hline \multirow{4}{*}{ Sampling technique } & Systematic random & 4 & 1,291 & $12.34(5.56,19.11)$ & $<0.001$ & 93.9 \\
\hline & Simple random & 2 & 560 & $19.08(15.82,22.33)$ & 0.669 & 0.0 \\
\hline & Convenience & 2 & 480 & $10.3(2.66,17.94)$ & 0.004 & 87.8 \\
\hline & Census & 3 & 1,324 & $19.22(8.84,29.6)$ & 0.003 & 88.7 \\
\hline
\end{tabular}

CG: Cockcroft-Gault; MDRD: Modification of Diet in Renal Disease equation; CKD-EPI: Chronic Kidney Disease Epidemiology Collaboration prediction equation.

Moreover, based on the pooled effects of five studies $[31,51-53,56]$, those who had a family history of CKD were nearly two times more likely to develop CKD than patients without a family history of CKD (OR $=1.61$; 95\% CI: 1.09 , $\left.3.23, I^{2}=65.6 \%\right)$. The details are presented in Figure 5.
3.8.2. Behavioral Factors. Most studies have reported that smoking, the use of traditional medicine, the habitual use of antipain drugs, and alcohol consumption are possible risk factors for CKD in patients with DM. Of these, only studies that reported data in terms of odds ratios, relative 
TABLE 4: Metaregression analysis for the included studies to identify the source(s) of heterogeneity.

\begin{tabular}{|c|c|c|c|c|c|c|}
\hline Variables & Category & Coef. & Std. error & $t$ value & $P$ value & (95\% conf. interval) \\
\hline Sample size & Total sample size & -0.0002 & 0.001 & -0.14 & 0.895 & $(-0.004,0.003)$ \\
\hline Year of publication & & 0.069 & 0.303 & 0.23 & 0.824 & $(-0.607,0.745)$ \\
\hline Region & $\begin{array}{c}\text { Amhara } \\
\text { Addis Ababa } \\
\text { Others (reference) }\end{array}$ & $\begin{array}{c}-0.011 \\
0.015\end{array}$ & $\begin{array}{l}2.851 \\
2.297\end{array}$ & $\begin{array}{c}-0.001 \\
0.001\end{array}$ & $\begin{array}{l}0.997 \\
0.995\end{array}$ & $\begin{array}{l}(-6.365,6.341) \\
(-5.104,5.134)\end{array}$ \\
\hline Study design & $\begin{array}{l}\text { Cross-sectional } \\
\text { Cohort (reference) }\end{array}$ & 0.8430 & 2.231 & 0.38 & 0.713 & $(-4.128,5.814)$ \\
\hline Type of DM & $\begin{array}{c}\text { Type } 2 \\
\text { Type } 1 \& 2 \text { (reference) }\end{array}$ & -0.102 & 2.260 & -0.05 & 0.965 & $(-5.139,4.934)$ \\
\hline GFR equation/formula & $\begin{array}{c}\text { MDRD } \\
\text { CKD-EPI } \\
\text { CG (reference) }\end{array}$ & $\begin{array}{l}0.099 \\
0.013\end{array}$ & 1.6461 .472 & $\begin{array}{l}0.06 \\
0.01\end{array}$ & 0.9530 .993 & $\begin{array}{l}(-3.568,3.767) \\
(-3.266,3.293)\end{array}$ \\
\hline Sampling technique & $\begin{array}{c}\text { Systematic random } \\
\text { Simple random } \\
\text { Census } \\
\text { Convenience (reference) }\end{array}$ & $\begin{array}{l}0.159 \\
0.542 \\
0.245\end{array}$ & $\begin{array}{l}2.244 \\
2.561 \\
1.678\end{array}$ & $\begin{array}{l}0.07 \\
0.21 \\
0.72\end{array}$ & $\begin{array}{l}0.945 \\
0.837 \\
0.563\end{array}$ & $\begin{array}{l}(-4.840,5.159) \\
(-5.166,6.250) \\
(-3.456,4.951)\end{array}$ \\
\hline
\end{tabular}

CG: Cockcroft-Gault; MDRD: Modification of Diet in Renal Disease equation; CKD-EPI: Chronic Kidney Disease Epidemiology Collaboration prediction equation.

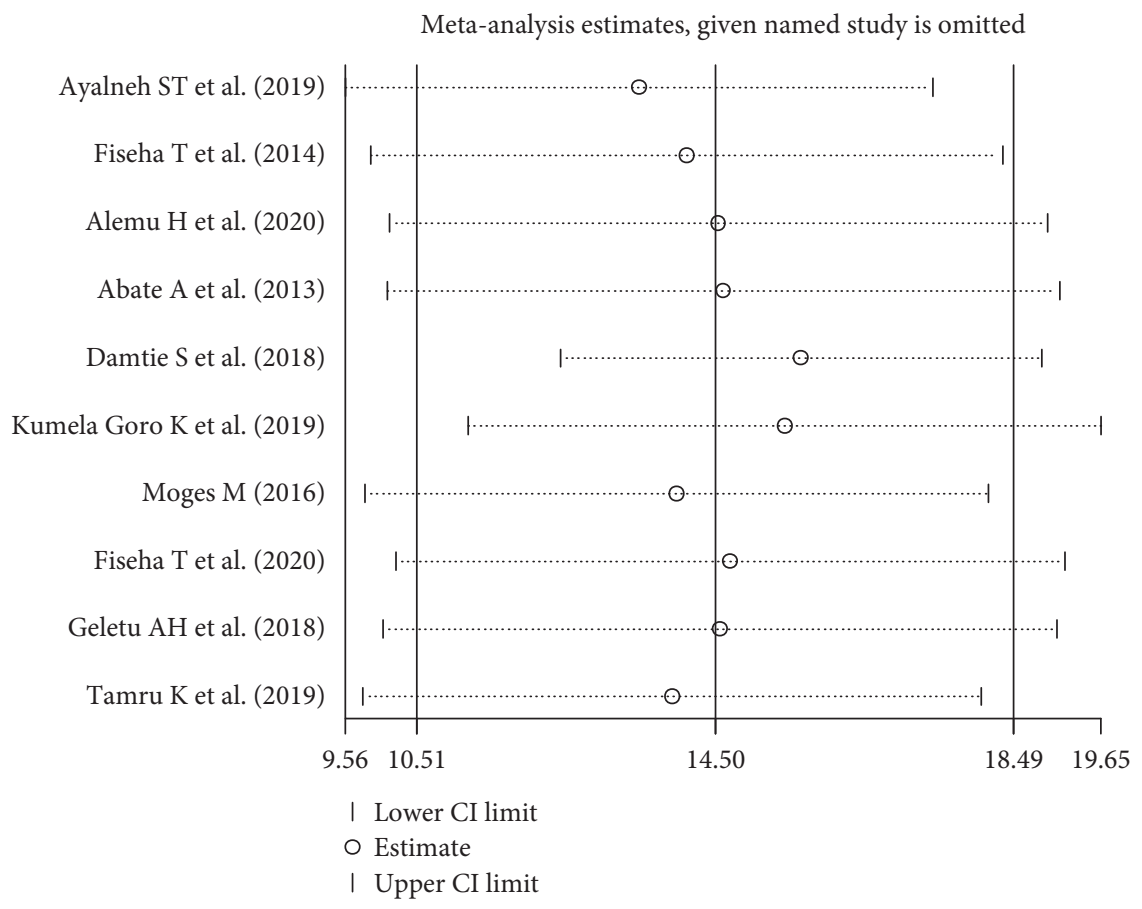

Figure 3: Results of the sensitivity analysis of the 10 studies.

risks, and categorical variables were included. The pooled effects of two studies $[54,56]$ showed that a habitual use of antipain therapy was nearly two times more likely to develop CKD in patients with DM than in patients who did not habitually use antipain therapy $(\mathrm{OR}=1.59 ; 95 \%$ CI: $0.88,2.87, I^{2}=0.0 \%$ ), although this association was not statistically significant. In addition, clients who had current alcohol consumption practices had no significant difference in the development of CKD compared with those who could not consume alcohol $(\mathrm{OR}=0.94 ; 95 \% \mathrm{CI}$ : $0.29,3.04, I^{2}=85.7 \%$ ) (Figure 6).

3.8.3. Clinical Factors. The pooled effects of five studies $[31,52-54,56]$ showed that the duration of diabetes for $>10$ years was statistically associated with CKD in patients with $\mathrm{DM}(\mathrm{OR}=2.76 ; 95 \% \mathrm{CI}: 1.38,5.51)$. The heterogeneity test $\left(I^{2}=83.6 \%\right)$ shows moderate evidence of variation across 


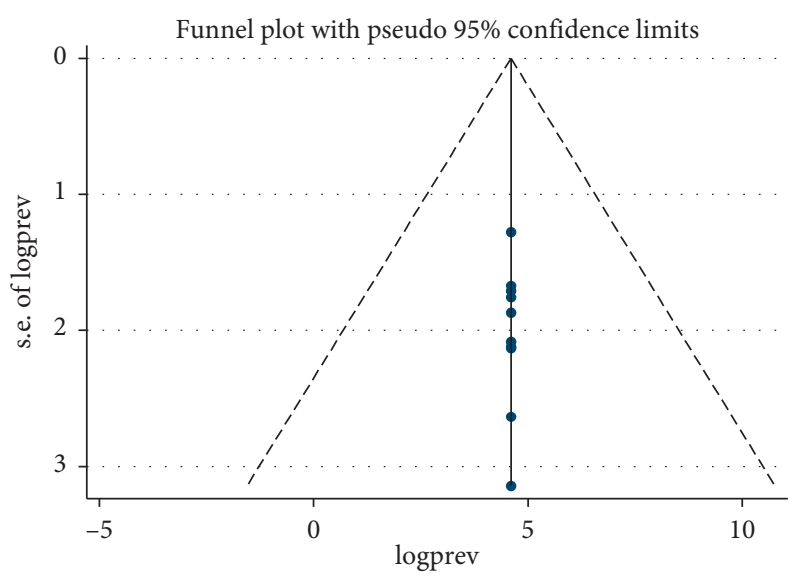

FIGURE 4: Funnel plot to test publication bias of the 10 studies.

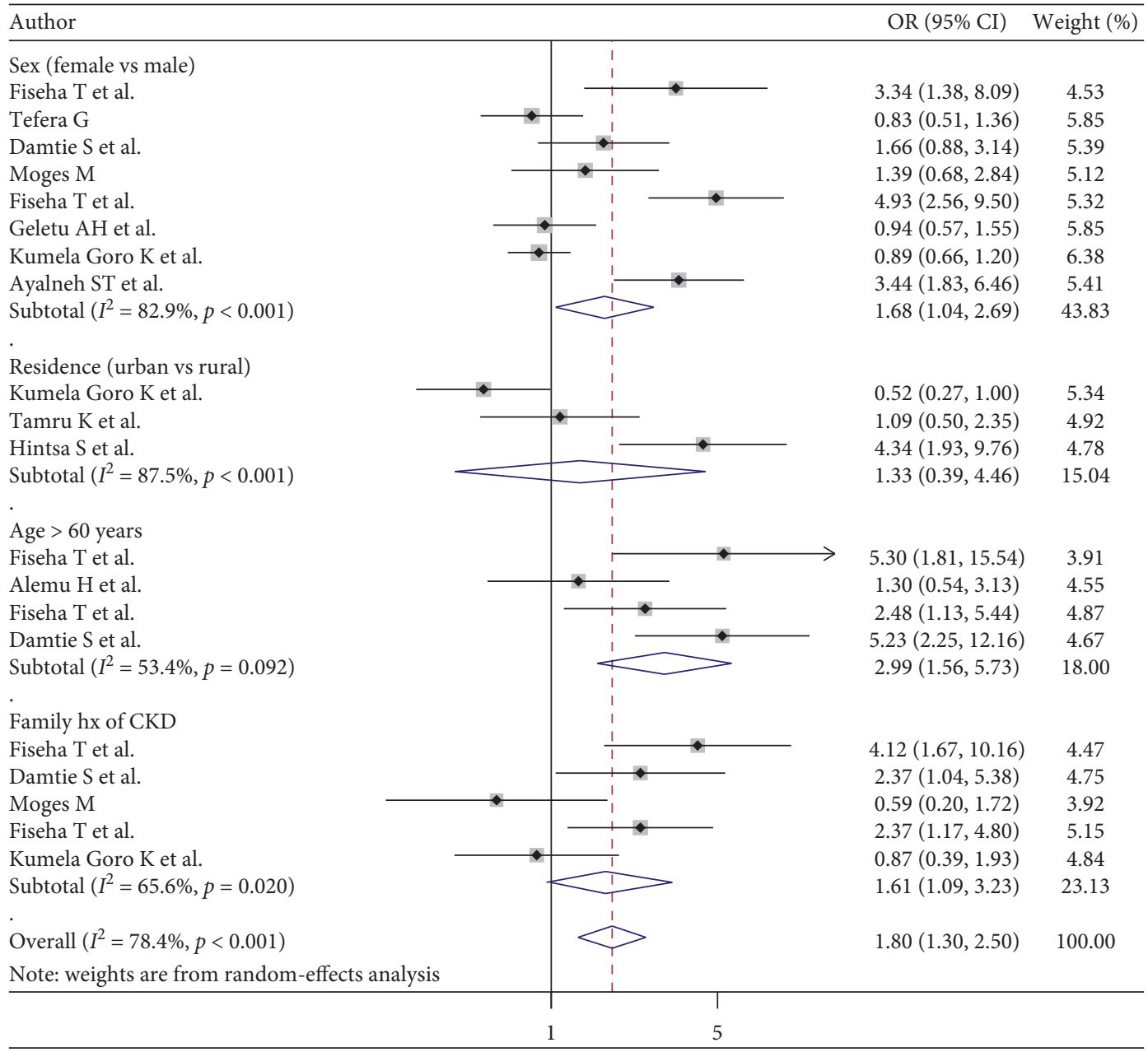

FIGURE 5: Sociodemographic factors associated with CKD in patients with DM.

studies. Additionally, patients with BMI $\geq 30 \mathrm{~kg} / \mathrm{m}^{2}$ were 2.51 times more likely to develop CKD than those with BMI $18.5-24.9 \mathrm{~kg} / \mathrm{m}^{2}\left(\mathrm{OR}=2.06\right.$; 95\% CI: $\left.1.41,3.00, I^{2}=46.8 \%\right)$ (Figure 7). Moreover, the pooled effects of six studies $[31,49,51-53]$ showed that those patients who had fasting blood glucose $>150 \mathrm{mg} / \mathrm{dl}$ were statistically associated with CKD in patients with DM $(\mathrm{OR}=2.58$; 95\% CI: $1.79,3.72)$.
The heterogeneity test $\left(I^{2}=0.0 \%\right)$ showed no significant evidence of variation across studies (supplementary file 4). On the other hand, the current meta-analysis showed that patients with high-density lipoprotein greater than $40 \mathrm{mg} / \mathrm{dl}$ were $52 \%$ less likely to develop CKD than patients with highdensity lipoprotein less than $40 \mathrm{mg} / \mathrm{dl}(\mathrm{OR}=0.48$; 95\% CI: $0.30,0.77, I^{2}=0.0 \%$ ) (supplementary file 5 ). 


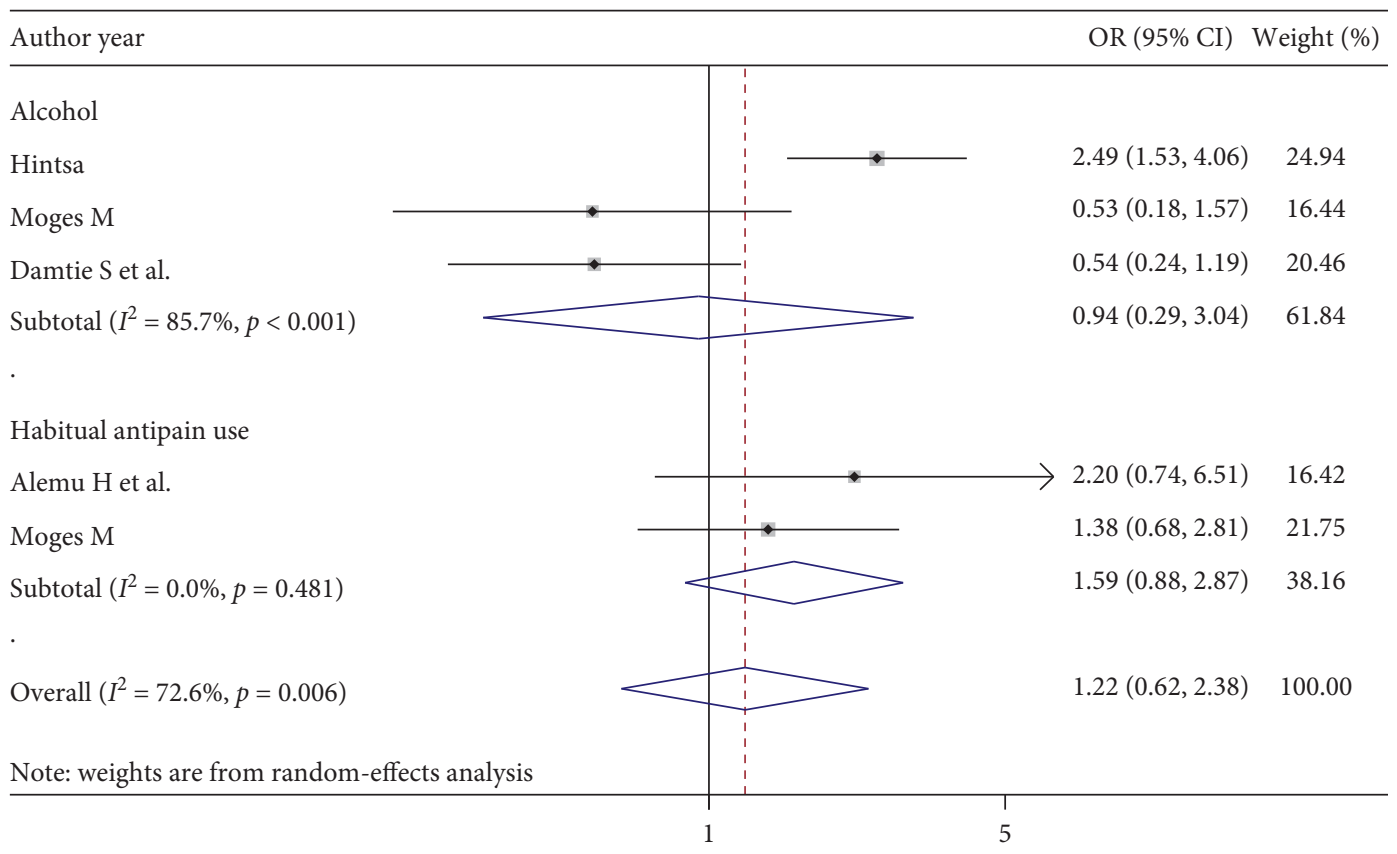

FIgURE 6: Behavioral factors associated with CKD among diabetes patients.

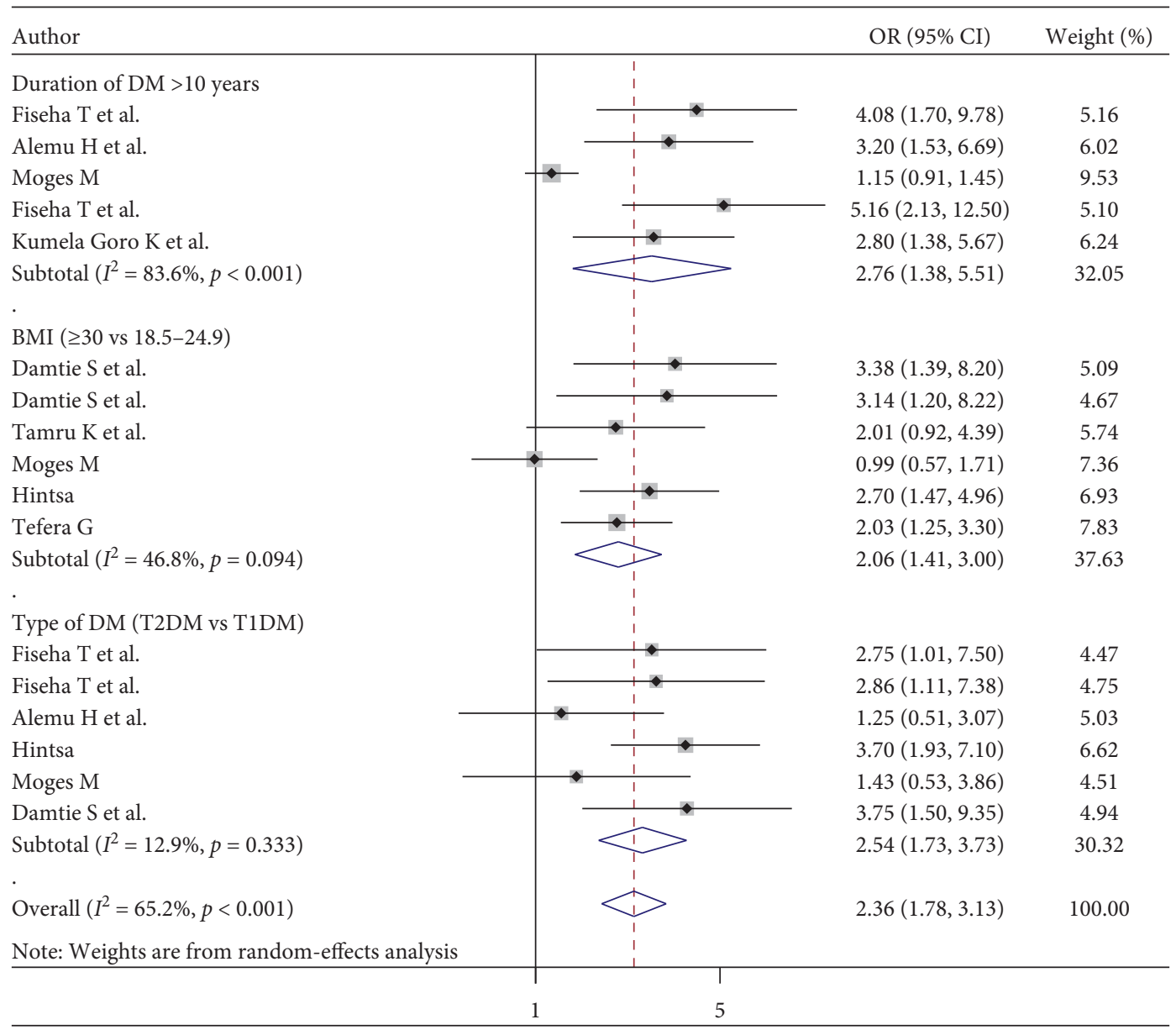

Figure 7: The effect of duration, BMI, and type of diabetes on CKD in patients with DM. 
3.8.4. Comorbidity-Related Factors. The pooled effects of four studies $[49,51,54,58]$ indicated that those patients who had systolic blood pressure $>140 \mathrm{mmHg}$ were 3.26 times more likely to develop CKD in patients with DM than SBP $<140 \mathrm{mmHg}\left(\mathrm{OR}=3.26\right.$; 95\% CI: 2.24, 4.74, $\left.I^{2}=10.6 \%\right)$. Additionally, nearly four patients who had diabetic retinopathy were more likely to develop CKD in patients with $\mathrm{DM}$ than in patients who did not have diabetic retinopathy $\left(\mathrm{OR}=4.54\right.$; 95\% CI: 1.08, 25.85, $\left.I^{2}=96.2 \%\right)$. Moreover, in our study, there was no statistically significant association between $\mathrm{CKD}$ and those who had cardiovascular disease $\left(\mathrm{OR}=1.64 ;\right.$ 95\% CI: 0.88, 3.06, $\left.I^{2}=0.0 \%\right)$ (Figure 8).

\section{Discussion}

In the present review, the pooled prevalence of CKD among diabetes patients in Ethiopia was estimated to be $35.52 \%$ for CKD stages 1 to 5 irrespective of the diagnostic criteria. Additionally, we found that $14.5 \%$ of diabetes patients have moderate or severe decreases in kidney function (i.e., CKD stages 3 to 5). The overall estimated prevalence of CKD stages 1 to 5 among diabetes patients found in our review was higher than that reported in the burden of CKD on the African continent (32.6\%) [59] and other systematic reviews conducted in Africa $(24.7 \%)$ [60]. The above disparities could be a systematic review conducted on the African continent, and all studies were low quality except for four with medium quality [60]. Moreover, differences in sample size, demographics, presence of comorbidities, difference definition used to determine renal failure, and clinical characteristics may contribute to such variation [61]. Furthermore, our findings suggest that the prevalence of CKD is substantially higher in people receiving care for DM, which further substantiates the call to integrate DM treatment with the care of other noncommunicable diseases.

Based on the eGFR estimation equation (CKD-EPI, CG, and MDRD) criteria used across the included studies, the highest prevalence of CKD stages 3 to 5 among diabetes patients (18.96\% (95\% CI: 14.93-22.99)) was reported across studies using the CG diagnostic criteria, and the lowest prevalence $(10.3 \%$ (95\% CI: $2.66,17.94)$ ) of CKD was reported across studies using the CKD-EPI definition as a diagnostic criterion. Similar findings in the variation of CKD prevalence per diagnostic criteria were also reported in a study conducted in different countries $[59,60]$. Though the CG equation showed a prevalence that was higher than the prevalence obtained in our findings using MDRD or CKDEPI equations, the validity of those methods in the Ethiopian context remains to be established [62].

Risk factor association was assessed in 11 of the 12 studies based on the pooled analysis of the adjusted odds ratio of studies. Systolic blood hypertension, high density lipoprotein $>40 \mathrm{mg} / \mathrm{dl}, \mathrm{BMI} \geq 30 \mathrm{~kg} / \mathrm{m}^{2}$, HbAlc $>7 \%$, fasting blood glucose $>150 \mathrm{mg} / \mathrm{dl}$, triglyceride $>150 \mathrm{mg} / \mathrm{dl}$, female sex, diabetic retinopathy, family history of $\mathrm{CKD}$, age $>60$ years, and duration of diabetes $>10$ years were associated with CKD in diabetic patients.
Although most of the studies to date reporting on sex differences in CKD associated with DM show either the male or female sex being a risk for CKD, a couple of studies have reported no effect of sex on CKD risk or progression $[63,64]$. However, the results of a recent study showed that female sex is at a higher risk of CKD in patients with DM than in men. This finding is consistent with previous research conducted in Bethesda [65] and Nigeria [11]. However, studies from Saudi Arabia [66] and Italy [67] showed that men with type 2 diabetes have a higher prevalence of diabetes nephropathy. The variation could be the fact that men have more muscle mass than women, and the differences in hormone metabolism and glomerular structure are assumed to play a role in the differences in prevalence of CKD observed between male and female genders [68]. Additionally, in the setting of diabetes, it is generally believed that female sex as a protective factor is lost even before menopause [69], possibly due to the imbalance in sex hormone levels and activity.

The present study revealed that age $>60$ years leads to a three times greater likelihood of developing CKD. This finding is in support of previous studies conducted in Nigeria [11] and a systematic review of diabetic nephropathy in Africa [70]. Therefore, our data remind clinicians to strengthen diabetes care programs to meet the rising challenge of CKD. Additionally, screening among such a highly selected population may help identify those that would most benefit from modifiable factors, including lifestyle changes, associated with the progression of diabetic CKD, especially in early stages [71]. The results of this study showed that the increased duration of the disease had a statistically significant effect on CKD in patients with DM. This finding is consistent with previous research conducted in Italy [67], Africa [70], and the UK [72]. This suggests that optimization of the delivery of diabetes care prior to the development of CKD may lead to a reduction in the incidence and progression of early diabetic CKD.

In accordance with previous longitudinal and metaanalysis studies $[66,67,70,73]$, we found that BMI $>30 \mathrm{~kg} /$ $\mathrm{m}^{2}$ was statistically associated with CKD incidence and progression in patients with $\mathrm{DM}$, with a moderate degree of heterogeneity in the meta-analysis ( $I$-squared value of $46.8 \%)$. Although the mechanisms that underlie the relationship between obesity and CKD are still poorly understood, some evidence has shown that excessive lipid deposition into the kidney as a result of obesity can also lead to the accumulation of toxic metabolites derived from fatty acid metabolism [74].

The current review shows that poor glycemic control $(\mathrm{HbAlc}>7 \%)$ is the most important risk factor for diabetic nephropathy. This was the same finding in different ethnic populations, as reported in Taiwanese [75], Saudi Arabia [66], and global meta-analysis studies [76]. In addition, the United Kingdom Prospective Diabetes Study (UKPDS) trial of patients with type $2 \mathrm{DM}$ and preserved kidney function demonstrated that intensive glycemic control targeting an HbA1C level of $<6-6.5 \%$ reduced the development and progression of diabetic nephropathy [77]. Moreover, additional studies should explore the physiopathological mechanism of $\mathrm{HbA1C}>7 \%$ that leads to renal complications. 


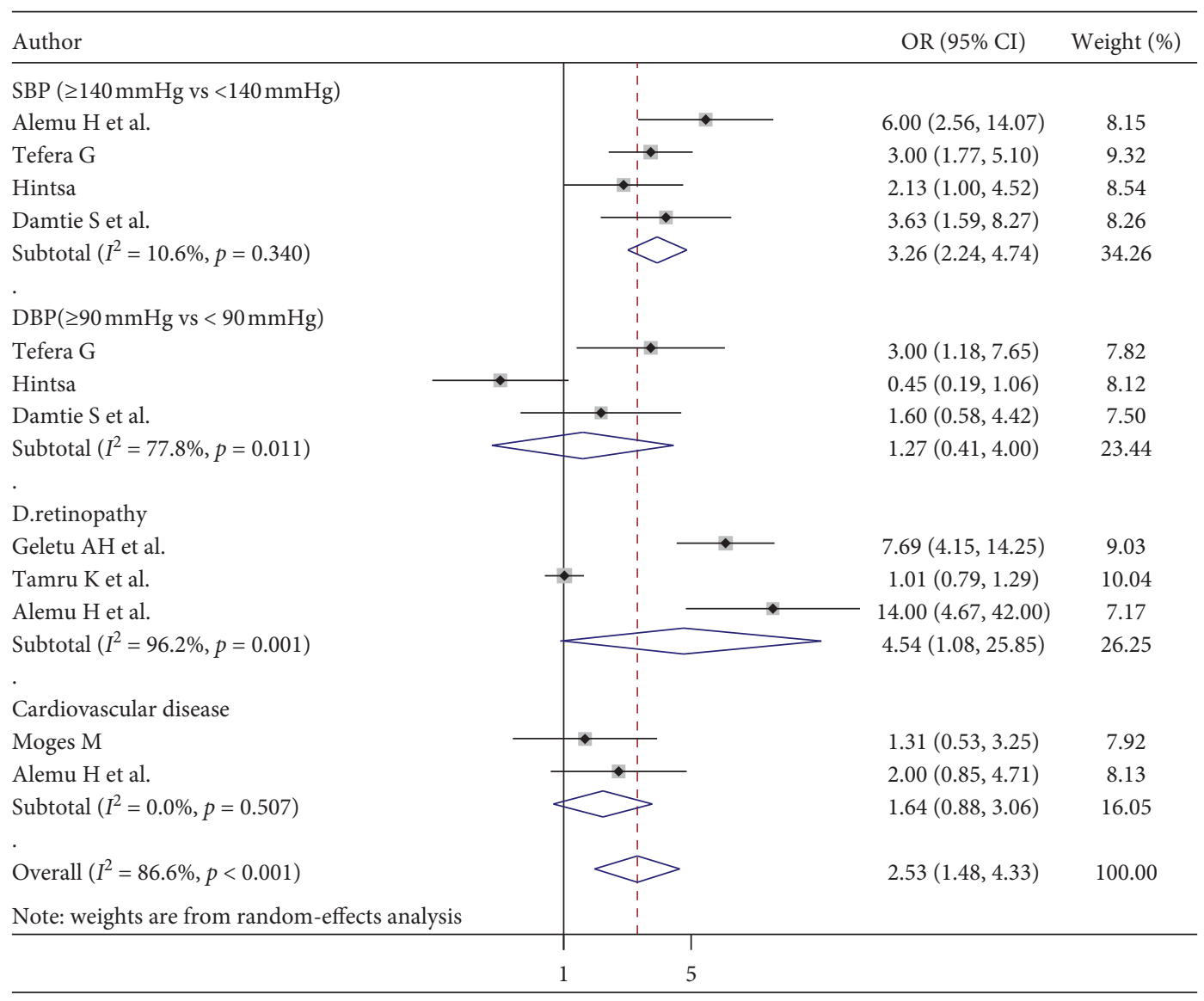

FIGURE 8: The effect of comorbidity-related factors on CKD inpatients with DM.

Chronic kidney disease onset was also predicted by the typical atherogenic lipid profile. In the current review, high levels of triglycerides were directly associated with an increased probability of developing reduced eGFR, whereas HDL-c levels decreased the onset of CKD. This finding was consistent with previous reports in Italy [67] and Taiwan [78]. Accordingly, Penno et al. recently confirmed the independent association between hypertriglyceridemia and CKD among patients with type 2 diabetes mellitus in a crosssectional study [79]. Therefore, our study verified that a stable HDL-C and a higher mean HDL-C are important protectors against the development of CKD in DM patients under a comprehensive diabetic care program.

The present study showed that systolic blood pressure greater than $140 \mathrm{mmHg}$ was a strong predictor of CKD in patients with DM. The results are consistent with those of previous systematic reviews and meta-analyses [70, 72]. Evidence also supports that early treatment of hypertension is important in preventing cardiovascular disease and the progression of diabetic renal disease and retinopathy [80], and the benefit of tight blood pressure control may be as great or greater than strict glycemic control [81]. In addition, another metaanalysis study reported that diabetic patients may benefit more from intensive BP-lowering strategies to provide protection against kidney failure events in patients with diabetes $[82,83]$.

In the present review, patients with diabetic retinopathy increased the risk of CKD by 4.54 times compared with those with no diabetic retinopathy, with a high degree of heterogeneity in the meta-analysis ( $I$-squared value of $96.2 \%$ ). This finding is in agreement with studies conducted in Korea [84], Saudi Arabia [85], and Singapore [86]. A possible explanation might be that patients with DR and diabetic CKD are both microvascular complications that lead to extravasation and inflammation [87]. Therefore, clinicians should evaluate DR severity at the first visit and closely monitor renal function and albuminuria in subjects with severe DR.

This study has implications for clinical practice. Estimating the national burden of CKD among diabetes patients should likely be established as the initial step in kidney disease prevention whenever affordable and feasible. Providing guidance to enhance awareness of CKD among health care professionals and patients and the promotion of healthy lifestyles should be engrained in preventive programs. Moreover, it provides information about the burden and public health impact of renal failure in the county for possible attention during routine clinical patient care. Furthermore, identifying risk factors may help health care professionals treat DM patients with CKD during their clinical care.

This systematic review is not free from limitations. First, there was a large discrepancy in the definitions used to identify CKD and the methods of creatinine measurement. Second, it may lack national representativeness because no 
data were found from all regions of the country. Third, the majority of the included studies were cross-sectional study designs and cause-effect relationships; therefore, they cannot be reflected in this review.

\section{Conclusion}

This study revealed that the prevalence of CKD remains high among diabetes patients in Ethiopia based on the 11 research-based papers included in this study. Its prevalence varies across countries in the region, with the highest prevalence in Addis Ababa. This study found that a long duration of DM, age $>60$ years, diabetic retinopathy, female sex, family history of CKD, poor glycemic control, systolic blood pressure, BMI $>30 \mathrm{~kg} / \mathrm{m}^{2}$, and high density lipoprotein $>40 \mathrm{mg} / \mathrm{dl}$ were significantly associated with an increased risk of CKD among diabetic patients. The findings provide a scientific basis for a further understanding of the risk factors of CKD in patients with DM and serve as a baseline for preventive strategies. Therefore, situation-based interventions and context-specific preventive strategies should be developed to reduce the prevalence and risk factors of CKD among diabetes patients.

\section{Abbreviations}

$\begin{array}{ll}\text { AOR: } & \text { Adjusted odds ratio } \\ \text { CI: } & \text { Confidence interval } \\ \text { CKD: } & \text { Chronic kidney disease } \\ \text { CKD- } & \text { Chronic Kidney Disease Epidemiology } \\ \text { EPI: } & \text { Collaboration prediction equation } \\ \text { DM: } & \text { Diabetes mellitus } \\ \text { eGFR: } & \text { Estimated glomerular filtration rate } \\ \text { MDRD: } & \text { Modification of Diet in Renal Disease equation } \\ \text { NOS: } & \text { Newcastle-Ottawa scale } \\ \text { PRISMA: } & \text { Preferred Reporting Items for Systematic } \\ & \text { Reviews and Meta-Analyses. }\end{array}$

\section{Data Availability}

The data used to support the findings of this study are available within the article and its supplementary information files.

\section{Conflicts of Interest}

The authors declare that they have no conflicts of interest.

\section{Authors' Contributions}

WSS and TYA developed the protocol and were involved in the design, selection of the studies, data extraction, statistical analysis, and development of the initial drafts of the manuscript. YAA and TYA were involved in data extraction, quality assessment, statistical analysis, and revising the manuscript. WSS and YAA prepared the final draft of the manuscript. All authors read and approved the final draft of the manuscript.

\section{Supplementary Materials}

Supplementary file 1: methodological quality assessment of the included studies was performed using the modified Newcastle-Ottawa Scale (NOS). Supplementary file 2: the risk of bias assessment tool for the included studies. Supplementary file 3: PRISMA checklist for meta-analysis of the prevalence of CKD among diabetes patients in Ethiopia. Supplementary file 4: the association of fasting blood glucose and glycemic control on CKD in patients with DM. Supplementary file 5: the effect of lipid profile on CKD in patients with DM. (Supplementary Materials)

\section{References}

[1] J. D. Kopple, "National kidney foundation K/DOQI clinical practice guidelines for nutrition in chronic renal failure," American Journal of Kidney Diseases, vol. 37, no. 1, pp. S66-S70, 2001.

[2] A. S. Levey, R. Atkins, J. Coresh et al., "Chronic kidney disease as a global public health problem: approaches and initiatives-a position statement from Kidney Disease Improving Global Outcomes," Kidney International, vol. 72, no. 3, pp. 247-259, 2007.

[3] B. Bikbov, C. A. Purcell, A. S. Levey et al., "Global, regional, and national burden of chronic kidney disease, 1990-2017: a systematic analysis for the Global Burden of Disease Study 2017," The Lancet, vol. 395, no. 10225, pp. 709-733, 2020.

[4] T. Liyanage, T. Ninomiya, V. Jha et al., "Worldwide access to treatment for end-stage kidney disease: a systematic review," The Lancet, vol. 385, no. 9981, pp. 1975-1982, 2015.

[5] M. Kerr, B. Bray, J. Medcalf, D. J. O'Donoghue, and B. Matthews, "Estimating the financial cost of chronic kidney disease to the NHS in England," Nephrology Dialysis Transplantation, vol. 27, no. 3, 2012.

[6] C. Garofalo, S. Borrelli, R. Minutolo, P. Chiodini, L. De Nicola, and G. Conte, "A systematic review and metaanalysis suggests obesity predicts onset of chronic kidney disease in the general population," Kidney International, vol. 91, no. 5, pp. 1224-1235, 2017.

[7] W. Chen, W. Chen, H. Wang et al., "Prevalence and risk factors associated with chronic kidney disease in an adult population from southern China," Nephrology Dialysis Transplantation, vol. 24, no. 4, pp. 1205-1212, 2009.

[8] M. K. Mau, M. R. West, N. M. Shara et al., "Epidemiologic and clinical factors associated with chronic kidney disease among Asian Americans and Native Hawaiians," Ethnicity \& Health, vol. 12, no. 2, pp. 111-127, 2007.

[9] C. Okwuonu, I. Chukwuonye, O. Adejumo, E. Agaba, and L. Ojogwu, "Prevalence of chronic kidney disease and its risk factors among adults in a semi-urban community of SouthEast Nigeria," Nigerian Postgraduate Medical Journal, vol. 24, no. 2, p. 81, 2017.

[10] A. J. Meremo, M. B. Masalu, I. Sabi et al., "Prevalence and risk factors associated with chronic kidney disease among patients presenting at a haemodialysis unit in dodoma, Tanzania," EA Health Research Journal, vol. 2, no. 1, pp. 53-57, 2018.

[11] I. Chukwuonye, O. Ogah, E. Anyabolu et al., "Prevalence of chronic kidney disease in Nigeria: systematic review of population-based studies," International Journal of Nephrology and Renovascular Disease, vol. 11, p. 165, 2018.

[12] T. Adugna, H. Merga, and E. K. Gudina, "Impaired glomerular filtration rate, high grade albuminuria and associated 
factors among adult patients admitted to tertiary Hospital in Ethiopia," BMC Nephrology, vol. 19, no. 1, p. 345, 2018.

[13] M. R. Moosa, I. Van der Walt, S. Naicker, and A. M. Meyers, "Important causes of chronic kidney disease in South Africa," South African Medical Journal, vol. 105, no. 4, pp. 320-327, 2015.

[14] T. Fiseha, T. Mengesha, R. Girma, E. Kebede, and A. Gebreweld, "Estimation of renal function in adult outpatients with normal serum creatinine," BMC Research Notes, vol. 12, no. 1, p. 462, 2019.

[15] K.-U. Eckardt, J. Coresh, O. Devuyst et al., "Evolving importance of kidney disease: from subspecialty to global health burden," The Lancet, vol. 382, no. 9887, pp. 158-169, 2013.

[16] R. K. Ephraim, S. Biekpe, S. A. Sakyi, P. Adoba, H. Agbodjakey, and E. O. Antoh, "Prevalence of chronic kidney disease among the high risk population in SouthWestern Ghana; a cross sectional study," Canadian Journal of Kidney Health and Disease, vol. 2, p. 76, 2015.

[17] L. Senevirathna, T. Abeysekera, S. Nanayakkara et al., "Risk factors associated with disease progression and mortality in chronic kidney disease of uncertain etiology: a cohort study in Medawachchiya, Sri Lanka," Environmental Health and Preventive Medicine, vol. 17, no. 3, p. 191, 2012.

[18] D. W. Johnson, E. Atai, M. Chan et al., "KHA-CARI Guideline: early chronic kidney disease: detection, prevention and management," Nephrology, vol. 18, no. 5, pp. 340-350, 2013.

[19] A. Shankar, R. Klein, and B. E. K. Klein, "The association among smoking, heavy drinking, and chronic kidney disease," American Journal of Epidemiology, vol. 164, no. 3, pp. 263271, 2006.

[20] M. J. Sarnak, A. S. Levey, A. C. Schoolwerth et al., "Kidney disease as a risk factor for development of cardiovascular disease," Circulation, vol. 108, no. 17, pp. 2154-2169, 2003.

[21] E. G. Lima, D. V. Batista, E. B. Martins, and W. Hueb, "Chronic kidney disease and coronary artery disease," Advances in Nephropathy, p. 193, 2018.

[22] Y.-G. Cherng, C.-S. Lin, C.-C. Shih et al., "Stroke risk and outcomes in patients with chronic kidney disease or end-stage renal disease: two nationwide studies," PLoS One, vol. 13, no. $1,2018$.

[23] P. S. Garimella and A. T. Hirsch, "Peripheral artery disease and chronic kidney disease: clinical synergy to improve outcomes," Advances in Chronic Kidney Disease, vol. 21, no. 6, pp. 460-471, 2014.

[24] E. Mohammed, L. D. Browne, A. Arun Kumar, F. Adeeb, A. D. Fraser, and A. G. Stack, "Prevalence and treatment of gout among patients with chronic kidney disease in the Irish health system: a national study," PLoS One, vol. 14, no. 1, 2019.

[25] O. A. Adejumo, I. O. Iyawe, A. A. Akinbodewa, O. S. Abolarin, and E. O. Alli, "Burden, psychological wellbeing and quality of life of caregivers of end stage renal disease patients," Ghana Medical Journal, vol. 53, no. 3, pp. 190-196, 2019.

[26] B. Assefa, B. Duko, G. Ayano, and G. Mihretie, "Prevalence and factors associated with depressive symptoms among patient with chronic kidney disease (CKD) in black lion specialized hospital and saint paulo's hospital millennium medical college, Addis Ababa, Ethiopia: cross sectional study," Journal of Psychiatry, vol. 19, no. 390, p. 2, 2016.

[27] C. Freeman, L. Giles, P. Field, E. Sörstadius, and H. van Haalen, "Humanistic burden and economic impact of chronic kidney disease: a systematic literature review," F1000Research, vol. 8, no. 2142, p. 2142, 2019.
[28] W.-S. Yeo and Q. X. Ng, "Disruptive technological advances in vascular access for dialysis: an overview," Pediatric Nephrology, vol. 33, no. 12, pp. 2221-2226, 2018.

[29] M. J. Shahwan, S. A. Gacem, and S. K. Zaidi, "Prevalence of diabetic nephropathy and associated risk factors among type 2 diabetes mellitus patients in Ramallah, Palestine," Diabetes \& Metabolic Syndrome: Clinical Research \& Reviews, vol. 13, no. 2, pp. 1491-1496, 2019.

[30] Y. Bentata, I. Haddiya, H. Latrech, K. Serraj, and R. Abouqal, "Progression of diabetic nephropathy, risk of end-stage renal disease and mortality in patients with type-1 diabetes," Saudi Journal of Kidney Diseases and Transplantation, vol. 24, no. 2, p. 392, 2013.

[31] T. Fiseha, M. Kassim, and T. Yemane, "Chronic kidney disease and underdiagnosis of renal insufficiency among diabetic patients attending a hospital in Southern Ethiopia," BMC Nephrology, vol. 15, no. 1, p. 198, 2014.

[32] A. A. P. F. Motala, E. Gouws, A. Amod, and M. A. Omar, "Microvascular complications in South African patients with long duration diabetes mellitus," South African Medical Journal, vol. 91, no. 11, pp. 987-992, 2001.

[33] G. Eknoyan, N. Lameire, K. Eckardt et al., "KDIGO 2012 clinical practice guideline for the evaluation and management of chronic kidney disease," Kidney International, vol. 3, no. 1, pp. 5-14, 2013.

[34] A. B. Adeniyi, C. E. Laurence, J. A. Volmink, and M. R. Davids, "Prevalence of chronic kidney disease and association with cardiovascular risk factors among teachers in Cape Town, South Africa," Clinical Kidney Journal, vol. 10, no. 3, pp. 363-369, 2017.

[35] A. Liberati, D. G. Altman, J. Tetzlaff et al., "The PRISMA statement for reporting systematic reviews and meta-analyses of studies that evaluate health care interventions: explanation and elaboration," Journal of Clinical Epidemiology, vol. 62, no. 10, pp. e1-e34, 2009.

[36] W. S. Shiferaw, T. Y. Akalu, M. Gedefaw et al., "Metabolic syndrome among type 2 diabetic patients in Sub-Saharan African countries: a systematic review and meta-analysis," Diabetes \& Metabolic Syndrome: Clinical Research \& Reviews, vol. 14, no. 5, pp. 1403-1411, 2020.

[37] D. W. Cockcroft and H. Gault, "Prediction of creatinine clearance from serum creatinine," Nephron, vol. 16, no. 1, pp. 31-41, 1976.

[38] A. S. Levey, J. B. Lewis, T. Greene, N. Rogers, and D. Roth, “A more accurate method to estimate glomerular filtration rate from serum creatinine: a new prediction equation," Annals of Internal Medicine, vol. 130, no. 6, pp. 461-470, 1999.

[39] A. S. Levey, L. A. Stevens, C. H. Schmid et al., "A new equation to estimate glomerular filtration rate," Annals of Internal Medicine, vol. 150, no. 9, pp. 604-612, 2009.

[40] Z. Munn, C. Tufanaru, and E. Aromataris, "JBI's systematic reviews," AJN, American Journal of Nursing, vol. 114, no. 7, pp. 49-54, 2014.

[41] G. A. Wells, P. Tugwell, D. O'Connell et al., The NewcastleOttawa Scale (NOS) for Assessing the Quality of Nonrandomized Studies in Meta-Analyses, Ottawa Hospital Research Institute, Ottawa, Canada, 2015.

[42] P. A. Modesti, G. Reboldi, F. P. Cappuccio et al., "Panethnic differences in blood pressure in Europe: a systematic review and meta-analysis," PLoS One, vol. 11, no. 1, Article ID e0147601, 2016.

[43] D. Hoy, P. Brooks, A. Woolf et al., "Assessing risk of bias in prevalence studies: modification of an existing tool and 
evidence of interrater agreement," Journal of Clinical Epidemiology, vol. 65, no. 9, pp. 934-939, 2012.

[44] T. B. Huedo-Medina, J. Sánchez-Meca, F. Marín-Martínez, and J. Botella, "Assessing heterogeneity in meta-analysis: $Q$ statistic or $I^{2}$ index?" Psychological Methods, vol. 11, no. 2, p. 193, 2006.

[45] M. Egger, G. Davey-Smith, and D. Altman, Systematic Reviews in Health Care: Meta-Analysis in Context, John Wiley \& Sons, Hoboken, NJ, USA, 2008.

[46] M. Borenstein, L. V. Hedges, J. P. T. Higgins, and H. R. Rothstein, "A basic introduction to fixed-effect and random-effects models for meta-analysis," Research Synthesis Methods, vol. 1, no. 2, pp. 97-111, 2010.

[47] StataCorp LLC, Stata Statistical Software (Version Release 14), StataCorp LLC, College Station, TX, USA, 2015.

[48] S. T. Ayalneh, M. G. Mesfun, G. Abebe, and H. Getachew, "Renal function assessment among diabetic patients in asella referral and teaching hospital, assela, south east Ethiopia," Science, vol. 8, no. 2, pp. 17-20, 2019.

[49] G. Tefera, "Determinants of proteinuria among type 2 diabetic patients at Shakiso health center, southern Ethiopia: a retrospective study," Advances in Diabetes and Metabolism, vol. 2, no. 3, pp. 48-54, 2014.

[50] A. Abate, W. Birhan, and A. Alemu, "Association of anemia and renal function test among diabetes mellitus patients attending Fenote Selam Hospital, West Gojam, Northwest Ethiopia: a cross sectional study," BMC Blood Disorders, vol. 13, no. 1, p. 6, 2013.

[51] S. Damtie, B. Biadgo, H. W. Baynes et al., "Chronic kidney disease and associated risk factors assessment among diabetes mellitus patients at a tertiary hospital, Northwest Ethiopia," Ethiopian Journal of Health Sciences, vol. 28, no. 6, p. 691, 2018.

[52] K. Kumela Goro, A. Desalegn Wolide, F. Kerga Dibaba et al., "Patient Awareness, prevalence, and risk factors of chronic kidney disease among diabetes mellitus and hypertensive patients at Jimma university medical center, Ethiopia," BioMed Research International, vol. 2019, Article ID 2383508, 8 pages, 2019.

[53] T. Fiseha and Z. Tamir, "Prevalence and awareness of chronic kidney disease among adult diabetic outpatients in Northeast Ethiopia," BMC Nephrology, vol. 21, pp. 1-7, 2020.

[54] H. Alemu, W. Hailu, and A. Adane, "Prevalence of chronic kidney disease and associated factors among patients with diabetes in northwest Ethiopia: a hospital-based cross-sectional study," Current Therapeutic Research, vol. 92, Article ID 100578, 2020.

[55] A. H. Geletu, A. S. Teferra, M. M. Sisay, and D. F. Teshome, "Incidence and predictors of chronic kidney diseases among type 2 diabetes mellitus patients at St. Paul's Hospital, Addis Ababa, Ethiopia," BMC Research Notes, vol. 11, no. 1, p. 532, 2018.

[56] M. Moges, Prevalence and Associated Factors of Chronic Kidney Disease Among Diabetic Patients that Attend Public Hospitals of Addis Ababa, Addis Ababa Universty, Addis Ababa, Ethiopia, 2016.

[57] K. A. F. Tamiru, E. Berhanie, Y. A. Aynalem, and W. S. Shiferaw, "Incidence of diabetic nephropathy in patients with type 2 diabetes mellitus at a tertiary healthcare setting in Ethiopia," Diabetes \& Metabolic Syndrome: Clinical Research \& Reviews, vol. 14, no. 5, 2020.

[58] S. D. L. Hintsa, M. Abay, T. Angesom, and A. Workicho, "Determinants of diabetic nephropathy in ayder referral hospital, northern Ethiopia: a case-control study," PLoS One, vol. 12, no. 4, Article ID e0173566, 2017.

[59] A. D. Kaze, T. Ilori, B. G. Jaar, and J. B. Echouffo-Tcheugui, "Burden of chronic kidney disease on the African continent: a systematic review and meta-analysis," BMC Nephrology, vol. 19, no. 1, p. 125, 2018.

[60] S. A. ElHafeez, D. Bolignano, G. D’Arrigo, E. Dounousi, G. Tripepi, and C. Zoccali, "Prevalence and burden of chronic kidney disease among the general population and high-risk groups in Africa: a systematic review," BMJ Open, vol. 8, no. 1, Article ID e015069, 2018.

[61] J. W. Stanifer, B. Jing, S. Tolan et al., "The epidemiology of chronic kidney disease in sub-Saharan Africa: a systematic review and meta-analysis," The Lancet Global Health, vol. 2, no. 3, pp. e174-e181, 2014.

[62] H. E. van Deventer, J. A. George, J. E. Paiker, P. J. Becker, and I. J. Katz, "Estimating glomerular filtration rate in black south Africans by use of the modification of diet in renal disease and Cockcroft-gault equations," Clinical Chemistry, vol. 54, no. 7, pp. 1197-1202, 2008.

[63] A. C. Ricardo, W. Yang, D. Sha et al., "Sex-related disparities in CKD progression," Journal of the American Society of Nephrology, vol. 30, no. 1, pp. 137-146, 2019.

[64] K. Rossing, P. K. Christensen, P. Hovind, L. Tarnow, P. Rossing, and H.-H. Parving, "Progression of nephropathy in type 2 diabetic patients," Kidney International, vol. 66, no. 4, pp. 1596-1605, 2004.

[65] C. Maric-Bilkan, "Sex differences in diabetic kidney disease," Mayo Clinic Proceedings, vol. 95, no. 3, pp. 587-599, 2020.

[66] K. Y. A. Al-Rubeaan, S. N. Subhani, N. A. Ahmad et al., "Diabetic nephropathy and its risk factors in a society with a type 2 diabetes epidemic: a Saudi National Diabetes Registrybased study," PLoS One, vol. 9, no. 2, Article ID e88956, 2014.

[67] S. V. F. De Cosmo, A. Pacilli, C. Giorda et al., "Predictors of chronic kidney disease in type 2 diabetes: a longitudinal study from the AMD Annals initiative," Medicine, vol. 95, no. 27, 2016.

[68] M. B. B. Hecking, J. Ethier, A. Kautzky-Willer et al., "Sexspecific differences in hemodialysis prevalence and practices and the male-to-female mortality rate: the dialysis outcomes and practice patterns study (DOPPS)," PLoS Medicine, vol. 11, no. 10, Article ID e1001750, 2014.

[69] C. A. Jones, A. S. Krolewski, J. Rogus, J. L. Xue, A. Collins, and J. H. Warram, "Epidemic of end-stage renal disease in people with diabetes in the United States population: do we know the cause?" Kidney International, vol. 67, no. 5, pp. 1684-1691, 2005.

[70] J. J. N. Noubiap and A. P. Kengne, "Diabetic nephropathy in Africa: a systematic review," World Journal of Diabetes, vol. 6, no. 5 , p. 759, 2015.

[71] D. Dunkler, M. Kohl, G. Heinze et al., "Modifiable lifestyle and social factors affect chronic kidney disease in high-risk individuals with type 2 diabetes mellitus," Kidney International, vol. 87, no. 4, pp. 784-791, 2015.

[72] C. C. W. Jadawji, C. Gillies, D. Kar, M. J. Davies, K. Khunti, and S. Seidu, "Prevalence and progression of diabetic nephropathy in South Asian, white European and African Caribbean people with type 2 diabetes: a systematic review and meta-analysis," Diabetes, Obesity and Metabolism, vol. 21, no. 3, pp. 658-673, 2019.

[73] R. Man, A. Gan, E. Fenwick et al., "The relationship between generalized and abdominal obesity with diabetic kidney disease in type 2 diabetes: a multiethnic asian study and metaanalysis," Nutrients, vol. 10, no. 11, p. 1685, 2018. 
[74] J. Hall, L. Juncos, Z. Wang, M. Hall, J. do Carmo, and A. da Silva, "Obesity, hypertension, and chronic kidney disease," International Journal of Nephrology and Renovascular Disease, vol. 7, p. 75, 2014.

[75] M.-Y. Lee, J.-C. Huang, S.-C. Chen, H.-Y. Chiou, and P.-Y. Wu, "Association of $\mathrm{HbAlC}$ variability and renal progression in patients with type 2 diabetes with chronic kidney disease stages 3-4," International Journal of Molecular Sciences, vol. 19, no. 12, p. 4116, 2018.

[76] D. F. Y. Cheng, Y. Liu, J. Li, Q. Xue, X. Wang, and N. Wang, "HbA1C variability and the risk of renal status progression in diabetes mellitus: a meta-analysis," PLoS One, vol. 9, no. 12, Article ID e115509, 2014.

[77] UK Prospective Diabetes Study (UKPDS) Group, "Intensive blood-glucose control with sulphonylureas or insulin compared with conventional treatment and risk of complications in patients with type 2 diabetes (UKPDS 33)," The Lancet, vol. 352, no. 9131, pp. 837-853, 1998.

[78] Y.-H. Chang, D.-M. Chang, K.-C. Lin, C.-H. Hsieh, and Y.-J. Lee, "High-density lipoprotein cholesterol and the risk of nephropathy in type 2 diabetic patients," Nutrition, Metabolism and Cardiovascular Diseases, vol. 23, no. 8, pp. 751757, 2013.

[79] G. S. A. Penno, G. Zoppini, C. Fondelli et al., "Hypertriglyceridemia is independently associated with renal, but not retinal complications in subjects with type 2 diabetes: a crosssectional analysis of the Renal Insufficiency and Cardiovascular Events (RIACE) Italian Multicenter Study," PLoS One, vol. 10, no. 5, Article ID e0125512, 2015.

[80] P. V. P. Gæde, H. H. Parving, and O. Pedersen, "Intensified multifactorial intervention in patients with type 2 diabetes mellitus and microalbuminuria: the steno type 2 randomised study," The Lancet, vol. 353, no. 9153, pp. 617-622, 1999.

[81] UK Prospective Diabetes Study Group, "Tight blood pressure control and risk of macrovascular and microvascular complications in type 2 diabetes: UKPDS 38," BMJ, vol. 317, no. 7160, pp. 703-713, 1998.

[82] J. C. Y. Wang, W. Xu, N. Lu, J. Cao, and S. Yu, "Effects of intensive blood pressure lowering on mortality and cardiovascular and renal outcomes in type 2 diabetic patients: a meta-analysis," PLoS One, vol. 14, no. 4, Article ID e0215362, 2019.

[83] S. G. I.-B. F. Coca, N. Haq, H. M. Krumholz, and C. R. Parikh, "Role of intensive glucose control in development of renal end points in type 2 diabetes mellitus: systematic review and metaanalysis," Archives of Internal Medicine, vol. 172, no. 10, pp. 761-769, 2012.

[84] H. C. L. Y. Park, A. Cho, C. H. Han et al., "Diabetic retinopathy is a prognostic factor for progression of chronic kidney disease in the patients with type 2 diabetes mellitus," PLoS One, vol. 14, no. 7, Article ID e0220506, 2019.

[85] J. S. Alwakeel, A. C. Isnani, A. Alsuwaida et al., "Factors affecting the progression of diabetic nephropathy and its complications: a single-center experience in Saudi Arabia," Annals of Saudi Medicine, vol. 31, no. 3, pp. 236-242, 2011.

[86] S. K. S. C. Low, L. Y. Yeoh, S. Tavintharan et al., "Prevalence of chronic kidney disease in adults with type 2 diabetes mellitus," Annals, Academy of Medicine, Singapore, vol. 44, no. 5, pp. 164-171, 2015.

[87] K. O. N. Matsuyama, M. Matsuoka, C. Shima, M. Wada, N. Jo, and M. Matsumura, "Relationship between pigment epithelium-derived factor (PEDF) and renal function in patients with diabetic retinopathy," Molecular Vision, vol. 14, p. 992, 2008. 